\title{
Research on Preparation and Propulsive Applications of Highly Concentrated Hydrogen Peroxide
}

\author{
Grzegorz Rarata, Wojciech Florczuk and Jaromir Smetek
}

Institute of Aviation, Warsaw, Poland

\begin{abstract}
Highly concentrated hydrogen peroxide has been widely used as a rocket mono-propellant and oxidiser since 1940's. Although the relevant specialist literature concerning HTP is relatively extensive, one can still find many myths about highly concentrated hydrogen peroxide, especially concerning safety aspects about its preparation by different techniques, handling or further utilisation. Such ambiguities can result in rather apprehensive approach towards preparing, utilising or even handling of HTP in relevant industry or research fields. The paper contains modern approach to laboratory preparation of highly concentrated solutions of hydrogen peroxide of HTP class (concentration $98 \%+$ ) that is intended for propulsive (rocket) applications. Authors, who have gained extensive experience in the field of HTP preparation, handling and utilisation, concisely explain facts and disprove some common myths concerning HTP. Additionally, advantages and possible application of $98 \%+$ solutions of HTP in various propulsive systems such as small satellites are described. The attention is also paid to the possibility of replacing currently used toxic and corrosive rocket propellants, such as hydrazine and its derivatives, RFNA (red fuming nitric acid), MON (mixed oxides of nitrogen) or NTO (dinitrogen tetroxide), by $98 \%+$ HTP. The potential of the medium as green and easy to handle propellant that can act both, as monopropellant or strong liquid oxidiser with hypergolic capability, is outlined briefly as well.
\end{abstract}

Key words: HTP, Hydrogen Peroxide, RGHP, oxidiser, green propellant, rocket propulsion

\section{Introduction}

HTP (High Test Peroxide, in the US also known as RGHP_-Rocket Grade Hydrogen Peroxide) still offers the aerospace community excellent opportunity of using an environmentally and personnel friendly and non-cryogenic, almost non-volatile oxidiser (or monopropellant) with greatly reduced toxicity, low storage and handling costs and relatively simple thruster or engine design. Hydrogen peroxide of propulsion grade has a significant heritage of the long term safe production and use for power and propulsive purposes [1,2]. Even richer experience with the use of different solutions of hydrogen peroxide has the industry (e.g. paper or fibre production), where the chemical is being utilised as a versatile oxidizing agent for organic and inorganic chemical processing as well as for semi-conductor applications, bleach for

Corresponding author: Grzegorz Rarata, Ph.D., research field: chemist in rocket propulsion. textiles and pulp, and a treatment for municipal and industrial waste with present world production that well exceeds 2 million tonnes per annum (as 100\%) and is still significantly growing [3].

The paper briefly presents various aspects of research on $98 \%+$ HTP preparation, handling and its utilisation in rocket propulsion systems being developed at IoA (Institute of Aviation, Poland). The experience of the authors clearly evidence that $98 \%+$ HTP may be applied successfully instead of hydrazine in monopropellant thrusters as well as it may act as an efficient oxidiser in bipropellant rocket propulsion systems also in hypergolic combination [4]. The authors also present the approach to the appropriately optimised catalyst bed design with the use of manganese oxides catalysts supported on alumina. The technology may be one of the key steps for near-future, durable catalysts for $98 \%+$ HTP decomposition in thrusters by providing a cost effective, yet simple and practical solutions. 


\section{HTP Propellant Preparation}

In general, there are several methods for preparation highly concentrated hydrogen peroxide of HTP class, especially $98 \%+$ grade, whereas in practice, only a few may be successfully and safely utilised. In the research laboratory practice, especially taking into account relatively larger amounts of HTP necessary for various research purposes or laboratory propulsion tests, there is only one method of HTP preparation that may be successfully applied, that is vacuum fractional distillation. Historically taking it was the first method of obtaining hydrogen peroxide of $80 \%$ and above in practical amounts. However, even today vacuum fractional distillation technique is the most versatile and important laboratory choice for obtaining larger amounts of HTP. As a matter of fact, a laboratory apparatus based on vacuum fractional distillation and made of special glass and kept at proper conditions during the process allows to obtain the purest product, with the concentration up to $99.9 \%$.

Other methods that allow to obtain $98 \%+$ HTP are fractional freezing and possibly sparging. The latter one involves bubbling warm dry air through a hydrogen peroxide solution and requires to use very pure batch product, pure air (gases) or/and purification of the final product. Besides, the efficiency of that method is rather low for higher concentrations of peroxide. The fractional freezing (crystallization) relies on the fact that below $62 \%$ water freezes before hydrogen peroxide, but in the case of solutions over $62 \%$ hydrogen peroxide freezes before water. Therefore, quite high concentrations can be achieved if the solution of peroxide over $62 \%$ is used, the ice is separated and after repeating the process relatively pure hydrogen peroxide can be obtained. However, the method seems to be very limiting (relatively low yield), requires highly concentrated raw peroxide and is also rather time-consuming.

\section{98\%+ HTP Preparation at IoA}

Due to the fact that hydrogen peroxide in liquid form is a mixture of two compounds that have quite different properties when turned into a vapour, the component parts have very different effects when hydrogen peroxide is evaporated. This especially concerns such parameters as relative vapour pressure of water and hydrogen peroxide. The latter has much lower vapour pressure than water. Additionally, aqueous solutions of hydrogen peroxide do not form an azeotropic mixture. Therefore, if an aqueous solution of hydrogen peroxide is allowed or forced to evaporate, much more water escape from the liquid phase tan peroxide. This is the basis for the most known laboratory technique for preparation (concentration) hydrogen peroxide-vacuum fractional distillation.

The method developed at IoA utilises a borosilicate glass apparatus that consists of the following main elements; a rotary flask as a vacuum evaporator that is linked to the smaller flask under the packed fractional column (silvered and vacuum isolated), receiver and vacuum and chilling systems. The raw batch solution of $60 \%$ reagent grade extra pure hydrogen peroxide is concentrated and then further purified via evaporation process and finally collected in the flask vessel under the column. The product is usually concentrated to 98.3-99.0\%, with TDS (Total Dissolved Solids) below $0.5 \mathrm{ppm}$ and $\mathrm{pH}$ below 2 (Fig. 1).

The sealed glassware of the apparatus is hold internally below 20 mbar during the first stage of the process, and below 5 mbar during the second one. The whole process of $1,500 \mathrm{~mL}$ batch takes no more than 7 hours, together with HTP collection, simple analysis and its stabilisation. It has been estimated that condensate drips into the collector flask with no more than a few percents loss. The circulation of cold water through a chiller, at the condenser coils, enables condensation with minimum losses. Vapours of hydrogen peroxide which escape the condenser are rendered harmless by the cold trap and eventually by dilution in the laboratory fume hood. Prepared by this method $98 \%+$ HTP is stored then in the special 


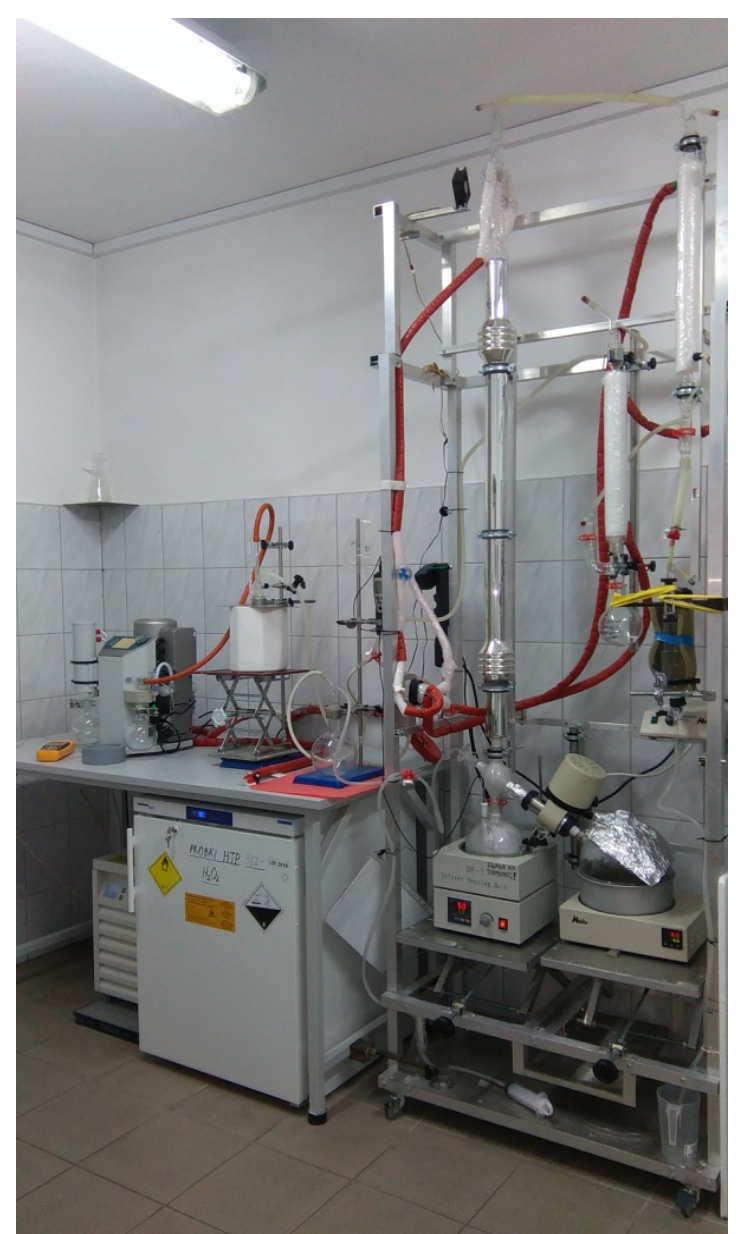

Fig. 1 The laboratory apparatus for preparing $98 \%+$ HTP at IoA research facility. containers with vent ports, since gradual decay to oxygen and water might, at least theoretically, cause pressure build-up and even the rapture of the vessel. However, the situation even with the slightest overpressure in the $98 \%+$ HTP (stabilized and non-stabilised) peroxide container was never observed so far by the authors.

Hundreds of litres of highly concentrated HTP of $98 \%+$ grade in concentration have been prepared at IoA laboratory facility for the various research and development project purposes (Fig. 2). The propellant obtained straight from the apparatus is chemically pure and inherently stable liquid propulsive medium. Slightly stabilised is then kept in controlled conditions in vented, usually one or five litre HDPE containers.

The medium has already proved to be actually very stable and storable liquid-some previous samples have been kept in passivated HDPE containers, refrigerated at $8{ }^{\circ} \mathrm{C}$ for over one year without any visible symptoms of decay (no detectable loss of concentration or tiny gas bubbles on the container surface). Sodium stannate $\left(\mathrm{Na}_{2} \mathrm{SnO}_{3} \cdot 3 \mathrm{H}_{2} \mathrm{O}\right)$ together with sodium nitrate have been used as stabilisers. Stannate hydrolyzes in $98 \%+$ hydrogen peroxide to

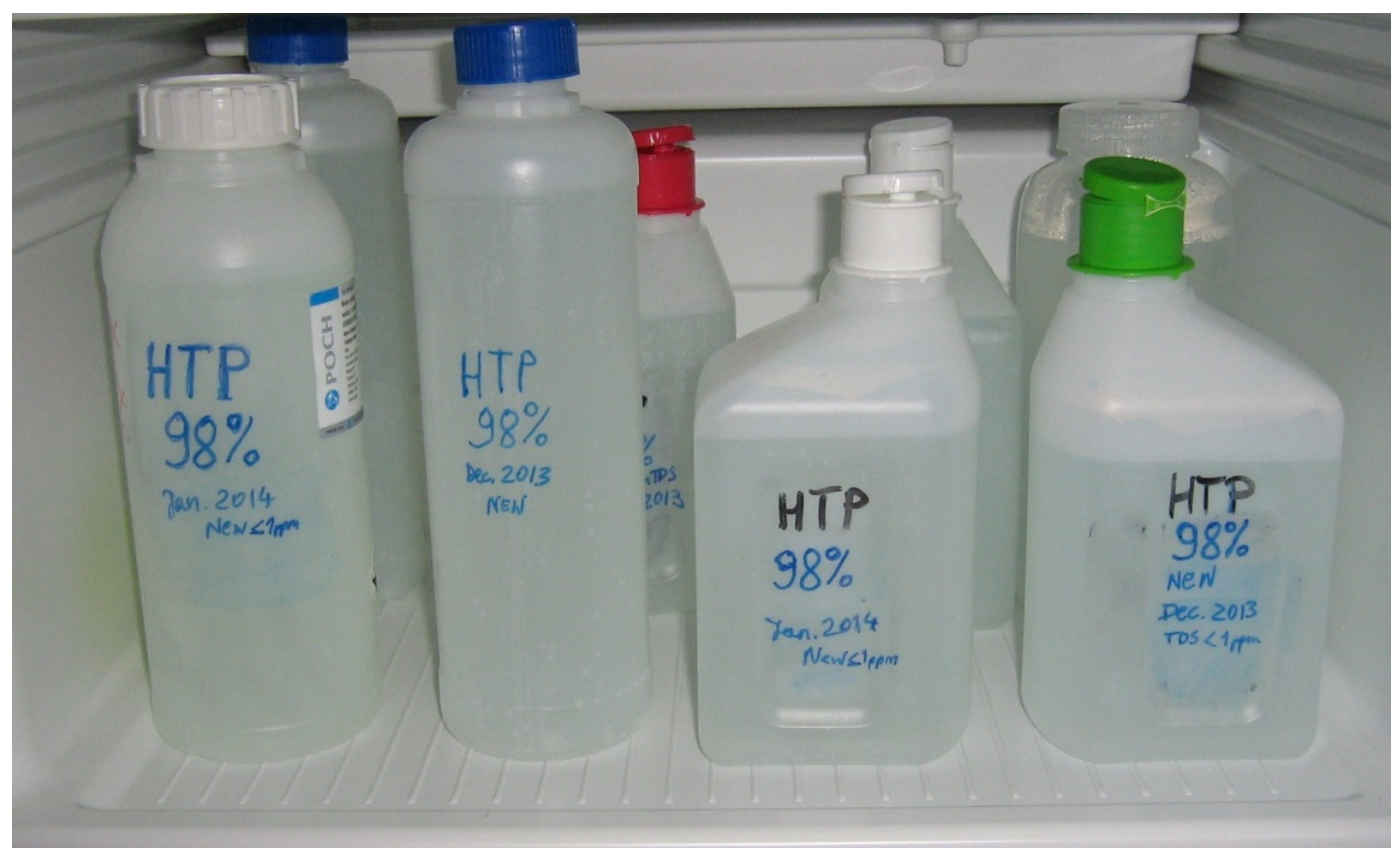

Fig. 2 The HDPE containers with one litre samples of $98 \%+$ grade, non stabilised HTP prepared at IoA. 
form a colloidal-hydrated stannic oxide $\left(\mathrm{SnO}_{2} \cdot \mathrm{xH}_{2} \mathrm{O}\right)$. Stabilization is then achieved by the adsorption of catalytic metallic cations, such as ferric ion $\left(\mathrm{Fe}^{3+}\right)$ and cupric ion $\left(\mathrm{Cu}^{2+}\right)$, by the colloid. It has been shown that sodium stannate greatly improves the stability of highly concentrated solutions of HTP stored in borosilicate glass vessels [5].

The first specification for the concentrated hydrogen peroxide solutions used as propellants was developed in the US during 1960's (known as MIL-P-16005) [6]. The specification was a result of many years of experience with this propulsive medium gained during its preparation, usage, storage and transportation (Table 1).

The table below shows the results from the analysis of $98 \%+$ HTP obtained according to the method described above (Table 2).

\section{Past Usage and Current Opportunities}

The large scale utilisation of hydrogen peroxide of HTP class as a propellant in the US had begun in the mid-1940's, with the seizure of German hydrogen peroxide propulsion technology. After the Second World War new concepts for concentrated hydrogen peroxide utilization were developed. It is worth to note that the medium was the first propellant used in the monopropellant thrusters for attitude control systems not only on satellite platforms but also on experimental aircrafts and further for launchers [7]. There is a lot of literature evidence that hydrogen peroxide was used in many US military projects, such as X-1, X-15, Mercury, Redstone, Centaur, SCOUT, SATAR, COMSAT, SYNCOM, and a few more. The development of rocket launchers in UK propelled by HTP as an oxidiser-the Black Knight and Black Arrow rockets was the culmination for the use of this medium in space programmes. The Black Arrow, three stages rocket launcher transferred British satellite into LEO orbit on 28 Oct. 1971 [1].

The current quest for hypergolic propellants have the origins in the beginning of the use of HTP as a rocket oxidiser. And presently quite a few promising fuels or mixtures that exhibit hypergolicity with HTP have been identified. However, most of them are so called catalytically promoted fuels where ignition phenomena relies on the decomposition of HTP during the contact. Then the decomposition reaction of HTP starts, the heat is liberated, some liquid is

Table 1 Allowable content of chemicals of $90 \%$ and $98 \%$ HTP according to the MIL-P-16005E specification [6].

\begin{tabular}{|c|c|c|}
\hline Hydrogen peroxide assay & $90.0-91.5$ & $98.0-99.0$ \\
\hline (percent by weight) & $0.5 \max$ & $0.5 \max$ \\
\hline Anions & $5.0 \max$ & $5.0 \max$ \\
\hline Chloride $\left(\mathrm{Cl}^{-}\right) \mathrm{mg} / \mathrm{kg}$ & $0.2 \max$ & $0.2 \max$ \\
\hline Nitrate $\left(\mathrm{NO}_{3}{ }^{-}\right) \mathrm{mg} / \mathrm{kg} 1$ & $0.5 \max$ & $0.5 \max$ \\
\hline Phosphate $\left(\mathrm{PO}_{4}^{-3}\right) \mathrm{mg} / \mathrm{kg}$ & $3.0 \max$ & $3.0 \max$ \\
\hline Sulphate $\left(\mathrm{SO}_{4}{ }^{-2}\right) \mathrm{mg} / \mathrm{kg}$ & $2 \max$ & $2 \max$ \\
\hline Ammonium $\left(\mathrm{NH}_{4}^{+}\right) \mathrm{mg} / \mathrm{kg}$ & $20 \max$ & $20 \max$ \\
\hline Stability $\left(24 \mathrm{~h} / 100^{\circ} \mathrm{C}\right)$ & $40 \max$ & $40 \max$ \\
\hline$\%$ loss of active oxygen & $0.35 \max$ & $0.35 \max$ \\
\hline Evaporation residue $\mathrm{mg} / \mathrm{kg}$ & $1.0-4.0$ & $1.0-4.0$ \\
\hline Total Carbon, mg/l & $0.03 \max$ & $0.03 \max$ \\
\hline Metals: & $0.03 \max$ & $0.03 \max$ \\
\hline Aluminium (Al) mg/l & $0.03 \max$ & $0.03 \max$ \\
\hline $\operatorname{Tin}(\mathrm{Sn}) \mathrm{mg} / \mathrm{l}$ & $0.03 \max$ & $0.03 \max$ \\
\hline Chromium (Cr) mg/l & $0.03 \max$ & $0.03 \max$ \\
\hline Lead $(\mathrm{Pb}) \mathrm{mg} / \mathrm{l}$ & $0.03 \max$ & $0.03 \max$ \\
\hline Manganese (Mn) mg/l & $0.03 \max$ & $0.03 \max$ \\
\hline Iron $(\mathrm{Fe}) \mathrm{mg} / \mathrm{l}$ & $0.03 \max$ & $0.03 \max$ \\
\hline Copper $(\mathrm{Cu}) \mathrm{mg} / \mathrm{l}$ & $0.03 \max$ & $0.03 \max$ \\
\hline Nickel (Ni) mg/l & $0.03 \max$ & $0.03 \max$ \\
\hline Antimony (Sb) mg/l & $0.03 \max$ & $0.03 \max$ \\
\hline
\end{tabular}


Table 2 The level of impurities detected in $98 \%+$ HTP sample before stabilisation by ion chromatography at the external chemical analysis laboratory and the requirements according to the MIL-P-16005E specification.

\begin{tabular}{|c|c|c|c|c|c|}
\hline \multicolumn{3}{|c|}{ Detected in $98 \%+$ HTP } & \multicolumn{3}{|c|}{ MIL Specification } \\
\hline $\mathrm{NH}_{4}^{+}$ & 0.173 & {$[\mathrm{mg} / \mathrm{kg}]$} & $\mathrm{NH}_{4}^{+}$ & 3 & {$[\mathrm{mg} / \mathrm{kg}]$} \\
\hline $\mathrm{Cl}^{-}$ & 0.077 & {$[\mathrm{mg} / \mathrm{kg}]$} & $\mathrm{Cl}^{-}$ & 0.5 & {$[\mathrm{mg} / \mathrm{kg}]$} \\
\hline $\mathrm{NO}_{3}^{-}$ & 0.108 & {$[\mathrm{mg} / \mathrm{kg}]$} & $\mathrm{NO}_{3}^{-}$ & 5.0 & {$[\mathrm{mg} / \mathrm{kg}]$} \\
\hline $\mathrm{PO}_{4}^{-3}$ & n.d. & {$[\mathrm{mg} / \mathrm{kg}]$} & $\mathrm{PO}_{4}^{-3}$ & 0.2 & {$[\mathrm{mg} / \mathrm{kg}]$} \\
\hline $\mathrm{SO}_{4}^{-2}$ & 0.040 & {$[\mathrm{mg} / \mathrm{kg}]$} & $\mathrm{SO}_{4}^{-2}$ & 0.5 & {$[\mathrm{mg} / \mathrm{kg}]$} \\
\hline $\mathrm{Al}$ & 0.0540 & {$[\mathrm{mg} / \mathrm{l}]$} & $\mathrm{Al}$ & 0.35 & {$[\mathrm{mg} / \mathrm{l}]$} \\
\hline $\mathrm{Sn}$ & 0.0004 & {$[\mathrm{mg} / \mathrm{l}]$} & $\mathrm{Sn}$ & $1.0-4.0$ & {$[\mathrm{mg} / \mathrm{l}]$} \\
\hline $\mathrm{Cr}$ & $<0.0009$ & {$[\mathrm{mg} / \mathrm{l}]$} & $\mathrm{Cr}$ & 0.03 & {$[\mathrm{mg} / \mathrm{l}]$} \\
\hline $\mathrm{Pb}$ & $<0.0001$ & {$[\mathrm{mg} / \mathrm{l}]$} & $\mathrm{Pb}$ & 0.03 & {$[\mathrm{mg} / \mathrm{l}]$} \\
\hline $\mathrm{Mn}$ & 0.0005 & {$[\mathrm{mg} / \mathrm{l}]$} & $\mathrm{Mn}$ & 0.03 & {$[\mathrm{mg} / \mathrm{l}]$} \\
\hline $\mathrm{Fe}$ & $<0.0108$ & {$[\mathrm{mg} / \mathrm{l}]$} & $\mathrm{Fe}$ & 0.03 & {$[\mathrm{mg} / \mathrm{l}]$} \\
\hline $\mathrm{Cu}$ & 0.0021 & {$[\mathrm{mg} / \mathrm{l}]$} & $\mathrm{Cu}$ & 0.03 & {$[\mathrm{mg} / \mathrm{l}]$} \\
\hline $\mathrm{Ni}$ & 0.0010 & {$[\mathrm{mg} / \mathrm{l}]$} & $\mathrm{Ni}$ & 0.03 & {$[\mathrm{mg} / \mathrm{l}]$} \\
\hline $\mathrm{Sb}$ & $<0.0003$ & {$[\mathrm{mg} / \mathrm{l}]$} & $\mathrm{Sb}$ & 0.03 & {$[\mathrm{mg} / \mathrm{l}]$} \\
\hline As & $<0.0005$ & {$[\mathrm{mg} / \mathrm{l}]$} & As & 0.03 & {$[\mathrm{mg} / \mathrm{l}]$} \\
\hline $\mathrm{Au}$ & $<0.0013$ & {$[\mathrm{mg} / \mathrm{l}]$} & $\mathrm{Au}$ & 0.03 & {$[\mathrm{mg} / \mathrm{l}]$} \\
\hline $\mathrm{Zn}$ & 0.0111 & {$[\mathrm{mg} / \mathrm{l}]$} & $\mathrm{Zn}$ & 0.03 & {$[\mathrm{mg} / \mathrm{l}]$} \\
\hline $\mathrm{Ti}$ & $<0.0008$ & {$[\mathrm{mg} / \mathrm{l}]$} & $\mathrm{Ti}$ & 0.03 & {$[\mathrm{mg} / \mathrm{l}]$} \\
\hline
\end{tabular}

n.d.: not detected.
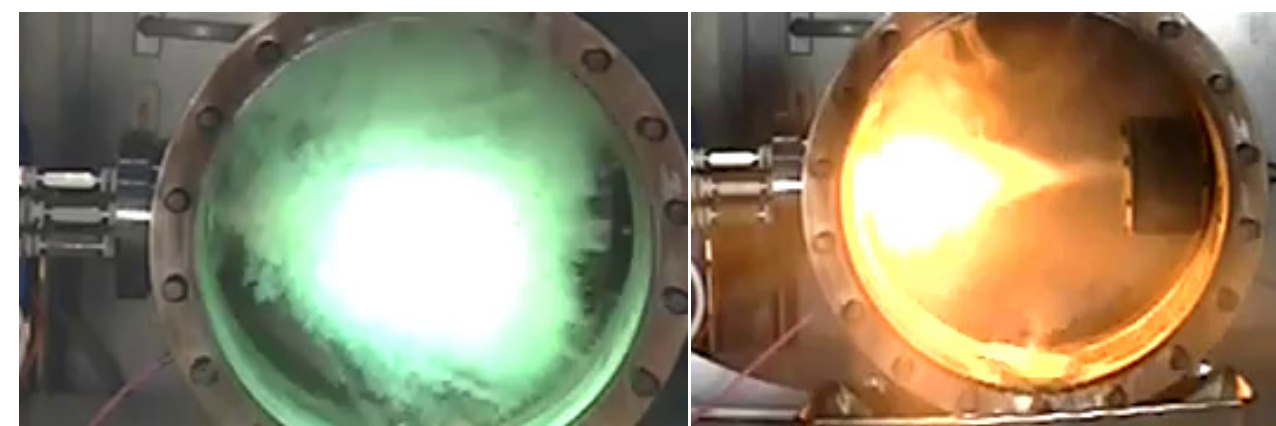

Fig. 3 The impinging tests of the hypergolic with $98 \%+$ HTP liquid propellants; left is MEA (monoethanoloamine) catalytically promoted with copper chloride and in the right picture is the mixture of MEA with dimethylamine promoted with strong reducing agent (sodium borohydride) (IoA).

vaporised and finally the fuel ignites. The decomposition of HTP is then a necessary condition for the state in which the auto-ignition temperature of the fuel is reached. As a result, many catalytically promoted fuels have relatively long ignition delay - due to the fact that the physical delay consist of not only atomization and vaporization but also mixing and decomposition of HTP.

Another group of fuels that are hypergolic with HTP constitute so called energetically promoted fuels. Usually it is an organic liquid or mixture with addition of strong reducing compound dissolved in it (e.g. hydride). In some cases the fuel might need no any additive, as it is inherently reactive towards HTP.

Some of ionic liquids are also good example of the compounds that may be inherently hypergolic with HTP [8]. These are liquid chemical compounds (salts with very low melting points) that typically show substantial advantages over common fuels or solvents, such as high stability, low toxicity, good solvent characteristics, and virtually no vapour pressure. Unconventional propellants based on energetic ionic 
liquids have been proposed. Some of them have already been proved to be fully hypergolic with $98 \%+$ HTP [9].

\section{Conclusions}

The paper presents that $98 \%+$ HTP may be applied instead of hydrazine monopropellant and it also might serve as an effective oxidizer in non-toxic bipropellant combinations. The medium has the potential for very high specific impulses and may be operated in a satellite propulsion system for a fraction of the cost of traditional propellants. With the correct materials of construction, properly prepared in the laboratory and conditioned, the chemical is very storable and stable — normally decomposing at extremely low rates. The tests done at IoA also show that the purity of $98 \%+$ HTP has significant and direct influence on its melting point. For example, for the ultra pure grade of $98 \%+$ HTP that has been obtained at IoA recently (TDS below $0.5 \mathrm{ppm}$ ) the attempts to freeze it, even at $-40^{\circ} \mathrm{C}$ for $12 \mathrm{~h}$, failed. Thus, it may be concluded that the liquid exhibits strong tendency to be super-cooled — far below its freezing point that is cited in the literature (about $-3{ }^{\circ} \mathrm{C}$ ) - it remains still liquid.

Therefore, in the opinion of the authors, the near future is in favour of the propulsion system that are based on $98 \%+$ HTP. High specific impulses propellants combinations with $98 \%+$ HTP are possible in bi-propellant mode, even as hypergolic ones. Moreover, the utilization of the highest grade of hydrogen peroxide in space sector can significantly decrease the total cost of the satellites missions, due to the low toxicity, high stability, long duration storability and safety of the medium. However, there are still a few issues such as efficient and reliable decomposition catalysts for $98 \%+$ HTP that need to be investigated further and more thoroughly.

\section{References}

[1] Wernimont, E., Ventura, M., Garboden, G., and Mullens, P. 1999. "Past and Present Uses of Rocket Grade Hydrogen Peroxide." General Kinetics, LLC Aliso Viejo, CA 92656.

[2] Ventura, M., Vernimont, E., Heister, S., and Yuan, S. 2007. "Rocket Grade Hydrogen Peroxide (RGHP) for Use in Propulsion and Power Devices-Historical Discussion of Hazards." AIAA 2007-5468.

[3] Crauser, G. 2015. "Peroxides - A growing and resilient cash generator." Capital Markets Day, June 10-11

[4] Rarata, G., and Florczuk, W. 2015. "Assessment of Various Fuel Additives for Reliable Hypergolic Ignition with 98\% + HTP." 66th International Astronautical Congress, Jerusalem, Israel.

[5] Monger, J. M. 1972. "Storable Concentrated Hydrogen Peroxide." Report No. 1, Shell Development Company.

[6] Wernimont, E., and Ventura, M. 2001. "Review of Hydrogen Peroxide Specification MIL-P-16005E." General Kinetics, LLC.

[7] Ventura, M., Vernimont, E., and Dillard, J. 2007. "Hydrogen Peroxide - Optimal for Turbomachinery and Power Applications.” AIAA 2007-5537.

[8] Schneider, S., Hawkins, T., Yonis, A., Rosander, M., Mills, J., and Hudgens, L. 2011. "Green Hypergolic Bipropellants: H202/Hydrogen-Rich Ionic Liquids.” Air Force Research Laboratory (AFMC), Edwards.

[9] Gilson, S., and Koshun, I. 2012. "Hypergolic Systems: A Review in Patents." J. Aerosp. Technol. Manag. 4 (4): 407-12. 